\title{
Influences of Social Psychology in the Pedagogical Approach of the Class of Students
}

Ștefănescu Andreia, Câmpean Zamfira-Cristina, Câmpean Titus-Gabriel 


\title{
Influences of Social Psychology in the Pedagogical Approach of the Class of Students
}

\author{
Ștefănescu Andreia ${ }^{a *}$, Câmpean Zamfira-Cristina $^{b}$, Câmpean Titus-Gabriel ${ }^{c}$ \\ ${ }^{a}$ Doctoral School "Educational, Reflection, Development", Babeş-Bolyai University, 7 Sindicatelor Street, 400029, Cluj-Napoca, Romania \\ ${ }^{b}$ School Inspectorate of Sălaj County, 2 Unirii Street, 457246, Zalau, Romania \\ "Arts College "Ioan Sima" Zalău, 9 Torentului Street, 450118, Zalau, Romania \\ *Corresponding author: stefanescu.andreia@gmail.com
}

Abstract

Keywords: school groups, group dynamics, group roles, teamwork, cooperation

\section{Zusammenfasung}

Schlüsselworte:

Schulgruppen,

Gruppendynamik,

Gruppenrollen,

Zusammenarbeit,

Zusammenarbeit
The study synthesizes the influences of social psychology on educational practice within the school context and circumscribes pedagogical and psychosocial perspectives that deal with the phenomena involved in the dynamics of the class-group. The class of students is the most interactive type of group and thus susceptible to instructive-educational training and psychosocial development, which makes this area of study extremely fertile for the psycho-educational policies oriented towards the formation of students with a view to optimal integration in their school environment.

Die Studie fasst die Einflüsse der Sozialpsychologie auf die pädagogische Praxis im schulischen Kontext zusammen und umschreibt pädagogische und psychosoziale Perspektiven, die sich mit den Phänomenen befassen, die an der Dynamik der Klassengruppe beteiligt sind. Die Klasse der Schüler ist der interaktivste Gruppentyp und daher anfällig für die pädagogische Ausbildung und psychosoziale Entwicklung, was diesen Studienbereich für die psychopädagogische Politik, die auf die Bildung von Schülern im Hinblick auf eine optimale Integration in ihr schulisches Umfeld ausgerichtet ist, äußerst fruchtbar macht.

\section{Introduction}

Studying the class of students from a pedagogical perspective has undergone various changes over time due to the development of the domain targeting the individual approach. If traditional pedagogy has placed the class of students at the center of its research, as a didactic and organizational process, contemporary pedagogy extends its focus on studies targeting socio-relational aspects and on complex dynamic structures that allow the connection of cognitive, affective, social and educational factors (Iucu, 2006). The latter approach can be supported by analyzing the branches of psychology, which can offer, in accordance to the principles and results of the research, an added value, possible to consider in order to optimize the instructive-educational context.

Social psychology exerts its influence on the educational process, and it considers the attempts to identify the problems of individual, relational and social nature, in order to optimize the quality of life. The Romanian psychosociologist Chelcea (1997) considers that social psychology represents "the study of the interaction of human psychic behaviours and processes, as well as the results of this interaction: collective mental states and processes, group situations, personality" (quoted by Iluț, 2009, p. 35). These elements are found in the class of students.

The purpose of the present study is to identify the elements brought by social psychology in approaching a class of students as a social group, in order to identify its relevance to the educational process. The interest in this topic is provided by the data found in the literature that underline the importance of the confluence of pedagogy with the social psychology in the formal educational context. In his studies, Zlate (1972) quotes the authors and their works: Piaget (1939) pointed out the need for the exchange of principles and techniques between the two fields, Debesse (1955) identified the need for a pedagogy 
supported by the data within psychology, Pieron (1957) outlined psycho-pedagogy on the basis of a pedagogy founded on child psychology and Oleron (1964) indicated that education developed through research focused on the psychology of learning represented an interest in the psycho-pedagogical context (authors quoted by Zlate, 1972).

The content reveals a comparative analysis of the class of students from the pedagogical point of view and of the social psychology in order to highlight the confluence between the two fields, to explain the path taken by social psychology in the study of the school groups and underline the influences brought by this field in the educational practice in the formal educational context.

The results of the paper are aimed at the contribution that social psychology has made to the study of the class group by identifying the elements that have developed and are preserved within the school and the educational context.

\section{Essential milestones of the psychosocial analysis of the class of students}

If pedagogy offers the overall image of the class, from the perspective of the dimensions that outline a specific profile, respectively a) ergonomic; b) psychological; c) social; d) normative; e) operational and, f) innovative (Iucu, 2006), social psychology identifies the existence of dynamics, functions, tasks, purpose, interactions, structures, processes and psycho-social phenomena, norms, group behaviours and performance (Cristea, 2015). They are important in relation to the class of students because a group should not be seen as a static entity. On the contrary, it has a certain dynamic, it goes through the stages of formation and evolution, it is subject to classification criteria and acquires its own characteristics.

From a pedagogical point of view, the ergonomic dimension considers the need to ensure the physical frame, by arranging the furniture and the appropriate arrangement of the classroom to correspond to the physical, biological and medical parameters. The psychological one emphasizes the importance of knowing the psycho-individual and age particularities, as well as the capacity to learn in different stages of human development. The social side offers the image of the class of students as a group within which an informational and relational structure is developed and maintained. The normativity encountered in the class of students has a constitutive role as kit regulates the modalities of conducting school activities. The procedures, strategies, methods and means chosen by teachers for the purpose of carrying out interventions aimed at conformity and compliance, behavioural changes for ameliorative purpose and so on, are included in the operational dimension. In trying to launch the concept of "changing education", defines innovation as "that change in the field of educational structures and practices that aims to improve the system." At the educational level, the innovative dimension is realized in the three levels of knowledge: a) past and present educational practice; b) the tendencies and traditions that underlie the educational activities; c) identification of the waiting horizons of the students (Iucu, 2006, p. 97)

The class of students, without disregarding elements belonging to the educational field, can be subjected to an analysis from the perspective of social psychology. The dynamics reflect "the development in time of the process of setting up and functioning of the group as a system" (Cristea, 2015). After 1940, the research of Lewin and his school, together with Lippitt and White, led to the emergence of the "group dynamics" theory (De Visscher \& Neculau, 2001, p. 11). The concept of "group dynamics" is used for the first time in articles written by Lewin, between 1944 and 1947, where "Dynamics: this word (...) denotes all the adaptive changes that occur in the overall structure of a group as a result of changes in the group. In some part of this group (...) in a group (...), something similar happens with the self-distribution of forces in a physical force field" (Krech \& Crutchfield, 1948 , pp. 22-23, quoted by De Visscher \& Neculau, 2001, p. 17). The functions highlight the role of the group in the whole of sub- and subordinate systems, with direct reference to the social integration, the accomplishment of the tasks, the differentiated satisfaction of the psychoindividual needs of the members, the assurance of the process of maintenance, development and maturity. The task is the key element of a group because its characteristics directly influence the formation and maintenance of relationships of a communicative, socioaffective, functional nature and so on. The purpose is the result of overlapping the characteristics of the tasks with the individual and collective motivations of the members of the group. The interactions, manifested at the communicative, informational, socio-affective, motivational level, for the purpose of interpersonal 
knowledge or for carrying out the task, concern all the relationships that are established between the members. Following these configurations, which become stable over time, psychosocial structures are formed. In their background, the types of interaction take the form of psychosocial communication processes, socio-affective, motivational-attitudinal and so on. The observable results of the development of psychosocial processes are the psychosocial phenomena, respectively cohesion, leadership, psychosocial climate and so on. Cohesion describes the attraction force that a group exerts on the component members, through functions of control, influence, pressure towards uniformity and so on, and the result is the feeling of belonging and unity, respectively "we". This is accompanied by group norms that are indispensable for establishing the members' behavioural benchmarks, depending on them being able to define positive phenomena such as conformity and compliance, or negative, such as deviance or delinquency, and group behaviours describe the development of group life. The performance obtained by the group is a synthetic indicator of the evaluation of the extent to which the basic functions are performed. In this sense, it can target the social, professional, educational level etc. (Cristea, 2015).

A common aspect of the sciences of social education and psychology is the study of groups, under particular aspects, and their dimensions. The definition given to the group of students, according to Webster's Dictionary (1989), is materialized in "reuniting a number of people, who have unifying relationships but also common characteristics. It presents itself as a living, dynamic, selfregulating system, which involves shared perceptions, multiple interactions with the school organizational environment" (quoted by Ionescu, 2007, p. 275). From a pedagogical perspective, the class of students (the group) represents "a dynamic ensemble in which formative processes are subordinated to the fundamental purpose, teaching, learning certain sets of information, attitudes and behaviours and which is constantly subject to the educational influences exercised by the school" (Iucu, 2006, p. 52).

\section{Consequences of the educational practice}

Influenced by theories that outline the definition of personality as a product of the interrelation between the social and cultural environment, to which is added the central idea of social constructivism, according to which individual knowledge and thinking are the direct result of the interactions and interdependencies that are created between the individual and the others, the socio-centric system arose (Vgotski, 1930; Mead, 1934; Piaget, 1969; Pieron \& Ruchlin, 1973; Buner, 1985; Bloom, 1969; 1971 - authors quoted by Cerghit, 2002). This model envisages the formation of the "social student" in the delimited space of the school formations under the influence of the education process, and this is possible to achieve if a number of conditions are met: a) the individual and social factors are equally important; b) the acceptance that the students' cognitive progress is influenced by the psychological and sociological variables; c) a "full" training is the result of a balance between the experiences acquired individually and those accumulated through social action (Cerghit, 2002).

The approach of the class of students from a psychosocial perspective aims at its association with the social group. This research direction is present in the literature from Romania and worldwide. Thus, Durkheim (1922), Wallon (1959), Jacard (1962), Girod (1962), Cantoni (1966), Chobaux and Filloux (1968) emphasize the importance of the process of "inter-influence" between the two fields, the sciences of education and social psychology (authors quoted by Zlate, 1972). The Romanian authors who have contributed in this field are Constantinescu (1966), Stoian (1966), Cazacu (1966, 1968), Zlate (1972), Păun (1982), Nicola (1996). The transfer of research data on small groups in the sphere of school groups was slow, because the focus was rather on explaining group phenomena and less on the formative nature of the group. Due to these coordinates, different authors such as Hopkins (1941), Baxter and Cassid (1943), Bradford and Lippit (1948), Trow (1950), Cunningham (1951), Passow and Mackensie (1952), started studying the dynamics of student groups (authors quoted by Zlate, 1972).

Romanian research in the field of social psychology has undergone similar stages of evolution with those of Western Europe or the USA, according to observations made by psychosociologists such as Tucicov Bogdan (1984), Chelcea (1998), Golu (2000), Neculau (1996), Zamfir (1997), Boncu (2002) and Cristea (2000) (authors quoted by Popoviciu, 2013, p. 23). Different influences of currents and schools, such as the pedagogy of the education groups and the sociometric technique, have made their mark on the investigations carried out in our country, but the socio-cultural values that influence the 
types of relationships have led to the emergence of some reflections and original literature, including teamwork, action group and mutual aid, types of aid from the rural world, emerging as a need for people to they resist together under adverse social or natural conditions (De Visscher \& Neculau, 2001).

The preoccupations of the social psychologists in Romania have expanded on the educational field, respectively, the class of students. In 1928, Professor Bârsănescu (quoted in De Visscher \& Neculau, 2001) conducts a "pedagogical inquiry", which helped him to highlight the existence of phenomena specific to the class of students he calls "psychosocial entity". He discovers the existence of "informal norms" by observing that "the teacher's use of the solidarity of the class members can lead to the formation of a psychic community of the class, to the orientation of the collective activity according to this common specific and the functioning of norms that he does not know and he only understands them." (De Visscher \& Neculau, 2001, p. 13). A research implemented by professor Petru in 1918, communicated in 1924 (quoted by De Visscher \& Neculau, 2002, p. 15), inspired by the social pedagogy of work, shows that the organization of the class was based on some coordination structures: the class council, the court, the judiciary committee, etc., and the functions were exercised by the students, chosen by the group. Basically, the behavior of the group members is shaped and modelled by practicing the interaction patterns imposed by the group dynamics.

This information is currently under the name of "group roles". Ten years later, between 1932-1939, Professor Popescu Teiușanu organizes "extracurricular activities", inspired by Sanderson's models in England and Peterson's in Germany. In 1938, Professors Narly and Zapan implement the "Vocational Observation Sheet" method that allows the evaluation of each student in the class in which he is integrated. In 1940, Herseni published a "Guidance for school sociograms", and in 1967, starting with the sociologist Mihu's essay on sociometry, the study of school groups aroused considerable interest (authors quoted in De Visscher \& Neculau, 2001). Psychological and sociological influences emphasized the education and training of children in the spirit of social solidarity, "replacing selfish competition and excessive rivalry with collaboration". These elements have become prerequisites for "new methods of education and training: teamwork in school communities and school groups, self-management of the class (informal leader) and of school, school courts, country education homes etc." (Bădina \& Neamtu, 1970, p. 20).

It is worth mentioning that "until the education reform of 1948, social psychology in Romania was more important, consuming western social psychology than producing native psychosociology, which does not mean that no significant field research has been done, natural or laboratory experiments. The most representative Romanian psychosociologists of this period have done specialized or doctoral studies abroad: Dimitrescu-Iași, Rădulescu-Motru, Herseni in Germany; Drăghicescu, Ralea and Pavelcu in France" (authors quoted in Chelcea, 2013, p. 79).

In the previous reports, references are made to the specialists' concerns regarding the socio-psychoeducational context in which the students are integrated. The mode of social interaction, the quality of the relationships and their effects on the optimal development of the students has been a common research topic for Durkheim, Hubert, Leroy, Lewin, Anderson and Wittmer (apud Iucu, 2006, p.14).

Social psychology has made its mark on the educational sciences through the offered functional character, identified at the following levels: a) elaboration of pedagogical theories based on psycho-sociological phenomena, such as the teamwork of children, formulated by Cousinet, Freinet \& Peterson and "non-directivism pedagogical", implemented by Rogers (apud. Zlate, 1972, p. 104); b) explaining the dynamics of the group of students by identifying the behavioral changes in the conditions of handling an educational variable, such as "teacher-centered teaching", "student-centered teaching" or "group-centered teaching"; c) offering intervention methods, adapted to the characteristics of the group of students; d) continuous training of teachers (Zlate, 1972).

The teacher-centered approach is based on "class leadership and control, understanding, cooperation, involvement, problem solving, affection and mutual respect" (Albu, 2002, p. 95). The directions of action consider the following proposals: "a) designing and planning ahead of the educational process, facilitating the introductory elements that will prepare the students/ students for the acquisition of the new contents; b) clear highlighting of the criteria of progress by the teachers and granting the appropriate learning time; c) use of discourse 
or lecture, explanation and demonstration as methods of transferring new content, to facilitate understanding-based learning; d) the involvement of students in collective discussions that will lead to the clarification of new contents and their integration in the old system, so that they can be used in daily life; e) concern for working in the bank or alternative activities, thus creating the road to individualized training; f) formulating homework, from the perspective of consolidating the learning process, but also of the involvement of parents" (Anghel, 2011, pp. 286-287). Snyders (1978) considers that the school population does not exhibit the psychological fragility that Rogers encounters in the psychiatric ward. Thus, "the teacher sets his goal to look at himself, to leave any point of view or personal judgment, to be as receptive to what others express, this being the meaning of acceptance" (Snyders, 1978, p. 112, quoted by Sălăvăstru, 2009, p. 118). Glasser (1992) believes that effective education occurs when students feel that they have the control to influence learning according to their needs, respectively, power and influence in the community, survival, to feel freedom, belonging and affection, to make choices, to play and entertainment. Glasser promotes the school that presents an educational offer corresponding to the needs of students' knowledge, and the information finds its applicability in everyday life. But in the classroom the teacher has a double role. On the one hand, it intends to develop the intellectual capacities that ensure the academic performance, and on the other hand, it is actively involved in the complex process of interaction and socialization within the class group (Babad, 2009). The interaction, communication and management of the student class are a set of elements that outline the competence of group-centered educational intervention. This is indispensable for a teacher because "keeping the class as a whole that works together and is oriented towards common tasks and establishing a learningfriendly environment are basic components of the successful management of the group of children or adolescents undergoing the learning process" (Anghel, 2011 , p. 290). The interaction with the group is based on different rules, procedures, monitoring and guidance strategies, both in terms of school content, and in the sphere of individual and group behaviours, within the institutionalized framework of the school.

\section{Discussions and conclusions}

The pedagogical perspective considers the group represented by the class of students through the formativeeducational processes of the school system, but it does not neglect the background of the group dynamics and the psycho-social influences generated by the interactions between the various actors. In studying the class of students, social psychology has focused on the way of social interaction, the quality of relationships and their effects on the optimal development of students. The influences of social psychology have led to the development of the concepts of "teamwork", "action group" and "types of help from the rural world", elements that are used with increasing frequency within the class group. Thus, the emphasis lies on social solidarity, respectively the replacement of competition and excessive rivalry with collaboration, which in the context of the present theoretical analysis implies group cohesion. Given that the school group is by its very nature a dynamic one, it is important to outline goals, types of norms (formal and informal), forms of leadership and "self-leadership of the class" through the informal leader and the roles underlying the formation of social profiles. Going forward, psychosociologists (Glassner, 1993) have developed a series of theoretical perspectives with practical openings on group cohesion, influence, decision making, interaction and communication, organizational models, the degree of autonomy and conformity, permeability or stability, with promising openings in studying these dimensions in the class of students. The pedagogical inquiry and the vocational observation record are tools designed to highlight social phenomena specific to the class of students, and its role was to stimulate the involvement of the group members in order to establish and function the informal norms, specific to each class of students. On the applicative level, inspired by Sanderson's models in England and Peterson's in Germany, in 1932-1939 Popescu Teiuşanu (quoted by De Visscher \& Neculau, 2001) begins to organize extracurricular activities in Romania. At present time, this activity has become a relatively common practice within schools. The innovation embedded in the idea of "changing education" implies the integration of complex dimensions of knowledge (including research): previous and contemporary educational practice, socio-cultural context and levels of expectation, respectively the types of expectations of students.

As an applicative contribution on the instructiveeducational dimension, social psychology has studied the 
dynamics of the class of students through the manipulation of some educational variables, respectively studentcentered teaching, group or teacher and pedagogical nondirectivism. For education sciences, the practical purpose of these approaches resides in identifying flexible intervention methods that consider the characteristics of the group of students and at the same time facilitate the life-long training of teachers.

\section{Authors note:}

Andreia Ștefănescu is a Doctoral Student at BabeșBolyai University Cluj-Napoca. She is currently studying the phenomenon of cohesion within schools groups currently the. Mrs. Ștefănescu is also President of the Romanian Association for Research and Innovation which provides professional training courses for teachers accredited by the Ministry of Education and Research. Mrs. Stefanescu Andreia.

Albulescu Ion is habilitated Professor and Ph.D. Coordinator at the Faculty of Psychology and Sciences of Education (Babeş-Bolyai University, Cluj-Napoca, Romania) Department of Educational Sciences, Faculty of Psychology and Educational Sciences. His research interest is reflected in a series of studies, articles and books published by prestigious international and national editors. Professor Albulescu teaching and research area covers several educational domains such as Educational Alternatives, Comparative Education, Pedagogical Theories and History of Educational Thinking etc.

Câmpean Zamfira-Cristina is currently a school inspector for Primary Education at Sălaj County School Inspectorate.

Câmpen Titus-Gabriel is Headteachers of "Ioan Sima" Arts College, Zalău, Sălaj County.

\section{References}

Albu, G. (2002). In the search of authentic education. Iași: Polirom Publishing House.

Anghel, E. (2011). Psychology of lifelong education: for specialists and adults interested in their own development. București: For You Publishing House.

Babad, E. (2009). The social psychology of the classroom. London: Routledge Publishing House.

Cerghit, I., (2002). Păun, E., Potolea, D. (eds.). Pedagogy. Theoretical fundaments and applicative endeavour. Iași: Polirom Publishing House.
Chelcea, S. (1982). The experiment in psychosociology. București: Scientific and Encyclopedic Publishing House.

Cristea, D. (2015). Treaty of social psychology. București: TREI Publishing House.

De Visscher, P., Neculau, A. (2001). Groups dynamic. Basic lectures. Iași: Polirom Publishing House.

Glasser, W. (1993). The quality school teacher - a companion volume to the quality school. New York: Harper Perennial.

Iluț, P. (2009). Social psychology and sociopsychology. Iași: Polirom Publishing House.

Ionescu, M. (coord.) (2007). Conceptual and applied approaches in educational sciences. Cluj-Napoca: Eikon Publishing House.

Iucu, R.B. (2006). Classroom management. Applications for the management of the educational crises situations. București: Polirom Publishing House.

Popoviciu, S. (2013). Social psychology. A contextual approach of the individual as social actor. Oradea: Emanuel University Publishing House.

Sălăvăstru, D. (2004). Psychology of education. Iași: Polirom Publishing House.

Sălăvăstru, D. (2009). Psychology of learning. Theories and educational applications. Iași: Polirom Publishing House.

Bădina, O. \& Neamtu, O. (eds.) (1970). Social pedagogy. Conceptions, approaches, and experiences in interwar Romania. București: Didactic and Pedagogic Publishing House.

Zlate, M., (1972). Social Psychology of classroom groups. București: Editorship of literature for Youth. 